\title{
O DISCURSO DA ÁREA DE SAÚDE SOBRE A EDUCAÇÃO A DISTÂNCIA FRENTE AOS PRINCÍPIOS DA EDUCAÇÃO E TRABALHO
}

\author{
Dalianne Lobo da Costa ${ }^{1}$ \\ José Lucas Pedreira Bueno² \\ Marco Antonio de Oliveira Gomes ${ }^{3}$
}

\section{RESUMO}

O presente trabalho busca compreender a separação da educação e trabalho com as implicações para a formação teórico-prática dos graduandos da área de saúde e como a área de saúde compreende a formação pela modalidade Educação a Distância (EAD), valendo da perspectiva que trabalho e educação eram desenvolvidos indissolúveis nas sociedades primitivas e que com o surgimento da propriedade privada e da divisão de classes sociais, a educação deixou de ser desenvolvida junto com o trabalho e que a EAD surgiu para atender segmentos da classe trabalhadora desprovida dos meios de produção e do acesso à educação tradicional. Assim, buscamos desenvolver uma pesquisa documental e bibliográfica, com objetivos descritivos, abordagem qualitativa do problema e de natureza básica. Podemos considerar que a formação do profissional da área de saúde passa por desafios e deve contribuir para a melhoria da qualidade de vida da população, alicerçada pelos princípios e diretrizes SUS. Porém o modelo universitário atual, com práticas de ensino tradicionais, distancia o conhecimento do aluno das reais necessidades do processo saúde-doença da população, não sendo isso um condicionante exclusivo da EAD, mas da separação do trabalho e educação.

Palavras-chave: Formação profissional; Área de saúde; Educação a distância; Trabalho e educação.

\section{SPEECH AREA HEALTH EDUCATION ON THE DISTANCE FRONT THE PRINCIPLES OF EDUCATION AND WORK}

\begin{abstract}
This paper seeks to understand the separation of education and work with implications for theoretical and practical training of the students of health and how health comprises training through distance mode (DE), using the perspective that work and education were developed indissoluble in primitive societies and the emergence of private property and the division of social classes, education ceased to be developed along with the work and DE was created to meet segments of the working class bereft of means of production and access to traditional education. Thus, we seek to develop a documental and bibliographic research, with descriptive objectives, qualitative approach to the problem and basic nature. We can consider that the formation of the healthcare professional goes through challenges and should contribute to improving the population's quality of life, supported by SUS principles and guidelines. However, the current university model with traditional teaching practices, distance the student's knowledge of the real needs of the process of population health and disease, if this is not an exclusive determinant of distance education, but the separation of work and education.
\end{abstract}

Keywords: Vocational training; Healthcare; Distance education; Work and education. 


\section{Introdução}

A separação da educação e trabalho não é um fenômeno recente. Surgiu com a propriedade privada e a divisão da sociedade em classes, desde a Antiguidade, quando também surgiram os primeiros delineamentos da institucionalização da escola. Verifica-se a partir desses marcos históricos a existência de dois tipos de educação: uma destinada aos que trabalhavam para a subsistência - aos filhos daqueles que exerciam atividades manuais e aprendiam no exercício do próprio trabalho, imitando aos mais velhos e outra que se destinava aos que trabalhavam para o acúmulo - aos filhos dos proprietários, para a aprendizagem do mando, do exercício do poder. A primeira pautava-se pela prática e a segunda pela teoria.

Mas foi sob a égide da educação pública institucionalizada para atender a demanda do meio de produção - que a cada momento histórico sofre transformações - que a questão da dissociação teoria e prática se ratificou intrínseca à educação. $\mathrm{O}$ advento da manufatura e a Reforma Protestante, também formam momentos marcantes para essa dicotomia, em que, por exemplo, o artesão medieval controlava todo o processo produtivo. Conhecia a matéria prima, as ferramentas necessárias para a confecção do produto e os meios de produzi-lo. E, na medida em que as relações capitalistas de produção se universalizam e as manufaturas ganham espaço, o artesão perde terreno e deixa de ser progressivamente um trabalhador que controla seus atos. Nas manufaturas, com a divisão cada vez mais acentuada do trabalho, não será necessário um artesão, mas apenas trabalhadores sem conhecimento específico sobre a produção trabalhando de forma fragmentada. Dessa forma, a burguesia se apropria do conhecimento. A teoria e a prática passaram a ser realizadas na formação profissional em momentos diferentes e num constante movimento de atender o discurso que defende sua indissociabilidade.

Nos dias atuais, as Instituições de Ensino Superior (IES) trabalham geralmente com momentos distintos para as atividades teóricas e práticas. Os currículos são comumente estruturados de forma disciplinar e cartesiana. Dificilmente dão conta de estabelecer a formação teórico-prática indissociavelmente, estabelecendo um conflito metodológico, que coloca em questão a formação prática-profissional, igualmente às demais áreas, também na área de saúde.

Sem desconsiderar a importância da formação teórica na área de saúde, a formação prática é tida como o momento régio para estabelecer o ambiente para a construção do perfil humanizado do futuro profissional, com aulas práticas em ambiente e tempo para a construção experiencial da prática laboral, frente às realidades da profissão em aprendizagem.

De forma agravada os cursos da área de saúde desenvolvidos pela modalidade de Educação a Distância (EAD) sofrem severas críticas devido ao que representantes da área de educação inferem sobre possíveis prejuízos da modalidade para a formação, dos quais destacamos três: inviabilidade de aulas práticas pela EAD, ausência da garantia de bons laboratórios, profissionais do setor administrativo e docentes qualificados. Tais considerações têm gerado debates na área de saúde e um esforço para impedir a oferta de cursos da área pela EAD. Igualmente, também têm gerado reflexões para o esclarecimento sobre as três questões levantadas, as quais buscaremos analisar por princípios mais amplos e contextualizados que o empirismo e o discurso sem referencial.

Partindo disso, destacamos que, em maio de 2011, aconteceu em Brasília, o "I Seminário sobre Ensino de Graduação a Distância na Área da Saúde", do Fórum dos Conselhos Federais da Área da Saúde (FCFAS), que contou com sessenta e um (61) representantes dos Conselhos Profissionais participantes do Fórum e suas comissões de 
ensino, para debaterem sobre a necessidade de compreensão do uso da "ferramenta da EAD" nos cursos de graduação a distância na área de saúde e elaborarem um documento relatório - para enviar ao MEC, para explicitar a posição do FCFAS quanto ao ensino superior a distância na área de saúde.

No entanto, aparentemente alienado da compreensão das consequências da separação da educação e trabalho ao longo da história da produção subjetiva e material da humanidade, no posicionamento legalista e aquém da realidade das IES no Brasil, o discurso do FCFAS (2011) proclama que, de acordo com as Diretrizes Curriculares Nacionais (DCN) e os princípios do Sistema Único de Saúde (SUS), os cursos de graduação deveriam ser interdisciplinares e interativos, com habilidades e competências específicas para cada curso da área da saúde, voltados para indissociabilidade de ensino, pesquisa e extensão e integrados com o ser humano em momentos presenciais, práticos e humanizados e que a EAD deveria garantir essas prescrições, mas desconsidera que muitos cursos presenciais também não as garantem.

A perspectiva FCFAS não distingue que a precarização da formação teórico-prática não é uma característica da EAD e sim do modelo educacional formal estabelecido sob influência do meio de produção. Por isso, o presente estudo visa explicitar analogias, com vistas a compreender até que ponto os argumentos do discurso dos Conselhos Federais da Área de Saúde alcançam uma lógica teórica, prática, legal e epistemológica ou se meramente reflete preconceito com a EAD.

As diversas críticas dos profissionais e dos Conselhos da área de saúde sobre a modalidade de a EAD abarcam o contexto da presente pesquisa que busca compreender pela história da educação a separação da educação e trabalho e suas implicações para a formação teórico-prática dos graduandos da área de saúde, apreciando os princípios legais para a implantação e regulamentação de cursos ofertados na modalidade a distância e a literatura especializada, para contribuir com subsídios para a formação na área de saúde no atual contexto político-educacional.

Para compreendermos o discurso da área de saúde sobre a EAD frente aos princípios da educação e trabalho é preciso entender a separação entre educação e trabalho determinada pelos meios de produção ao longo da história da humanidade, que se reproduzem no modelo educacional de cada momento histórico, conforme será tratado a seguir.

\section{Princípios da educação e trabalho}

Nas sociedades primitivas o trabalho e a educação eram desenvolvidos juntos. Ao produzir para a subsistência, os homens aprendiam a produzir, pela forma que lidavam com a natureza e com que se relacionavam em grupos e isto era levado para as outras gerações, pela reprodução de hábitos e costumes, transferidos principalmente pela oralidade. Nessa época não existia a educação formal. Assim, os homens aprendiam a produzir a subsistência e ensinavam as futuras gerações no campo de trabalho. O meio de produção era comum, podendo ser denominado de "comunismo primitivo". Não existia a propriedade privada, nem a divisão do trabalho em manual e intelectual, não havia classes sociais e o trabalho era realizado para a subsistência, não para o acúmulo (SAVIANI, 2007).

O que configurava o processo de aprendizagem era a experiência no trabalho, assim, “a expressão 'educação é vida', e não preparação para a vida, reivindicada muitos 
séculos mais tarde, já na nossa época, era, nessas origens remotas, verdade prática" (SAVIANI, 2007, p. 156).

Com a ampliação da produção, a partir do domínio do homem sobre a natureza, pela apropriação material, que as sociedades acumularam no decorrer da história e na medida em que o homem se fixou na terra, houve o surgimento da propriedade privada e a divisão de classes e do trabalho. Passaram a existir os proprietários dos meios de produção, que naquele momento histórico era a terra, e os desprovidos dos meios de produção. A educação deixou de ser desenvolvida concomitante ao ato do trabalho e os filhos dos proprietários foram para a escola para receberem uma educação diferenciada, voltada para a arte da palavra, atividades lúdicas ou militares. Os filhos dos não-proprietários mantiveram a formação no trabalho, aprendendo na prática. Esta primeira separação do trabalho e educação já demarcou e ratificou de geração a geração a separação das classes sociais na Antiguidade (SAVIANI, 1994).

A educação na época do escravismo antigo deu origem à escola, que ocorreu principalmente na Grécia e Roma, voltada para os filhos dos proprietários dos meios de produção.

A palavra escola deriva do grego e significa, etimologicamente, o lugar do ócio, tempo livre. Era, pois, o lugar para onde iam os que dispunham de tempo livre. Desenvolveu-se, a partir daí uma forma específica de educação, em contraposição àquela inerente ao processo produtivo. Pela sua especificidade, essa nova forma de educação passou a ser identificada com a educação propriamente dita, perpetrando-se a separação entre educação e trabalho (SAVIANI, 2007, p.155).

Algumas peculiaridades da Antiguidade puderam ser observadas na Idade Média, pois a divisão da educação entre classes sociais ainda permaneceu. Nessa época, a educação passou a ser oferecida pela Igreja Católica, pela escola confessional, que se destinava aos filhos dos proprietários. Para essa escola foi cunhada a expressão "ócio com dignidade", pois era onde se praticavam as atividades educacionais da classe dominante, que se assemelhava à educação da Antiguidade.

Ocupar o ócio com os estudos significava não precisar trabalhar para suprir as necessidades da existência. Ocupar o ócio com dignidade é ocupá-lo com atividades consideradas nobres e não com atividades consideradas indignas (SAVIANI, 1994, p. 154).

Como já visto que são as mudanças nos e dos meios de produção que determinam os caminhos das instituições sociais, sendo a escola e as IES essas instituições, elas também sofreram mudanças que redefiniram formas e papéis na sociedade, diante dos marcos históricos da Revolução Francesa e da Revolução Industrial.

Foi a partir da Revolução Francesa que fortaleceu a defesa da educação pública, já que o discurso de uma classe de ideólogos burgueses que defendiam que todos deveriam ir para a escola começou a ter forte influência na sociedade da época. Desta forma, a escola deveria ser universal e igualitária, comum a todos os homens. Outro discurso sobre a educação pública que também surgiu e influenciou os caminhos da formação escolar defendia que a escola deveria ser somente para os filhos dos burgueses e que era inviável para os trabalhadores frequentarem a escola, pois enquanto estavam estudando, não poderiam estar auxiliando a produção de mais capital. E houve alguns "visionários", economistas políticos, que defenderam a escola para os trabalhadores, desde que fosse 
ofertada somente até o nível básico, a fim de proporcionar o mínimo de instrução e garantir o avanço da sociedade letrada (SAVIANI,1994).

Após a Revolução Industrial os meios de produção passaram a demandar de maneira sine qua non a educação escolar para dotar o trabalhador de determinadas habilidades que o pudessem fazer operar as máquinas e consequente manter a subsistência. A partir da transferência do trabalho manual para o maquinário industrial e da divisão do trabalho, os meios de produção - agora as indústrias e não mais a terra - passaram a demandar qualificação especializada do trabalhador.

E assim a separação das classes no âmbito da educação permaneceu como forma de distinção entre "filhos dos providos" e "filhos dos desprovidos" dos meios de produção, continuando, desde então, duas escolas que definem o sistema educacional capitalista - a dos ricos e a dos pobres. O principal agravo é que o sistema educacional capitalista não conseguiu e não objetiva suprir, de forma universalizada, o acesso ao conhecimento, ratificando as condições dos desprovidos.

Sobre o sistema educacional da sociedade capitalista, Saviani (1994, p. 160) relata que, sob a ótica capitalista, a educação para o trabalhador deve ocorrer de tal forma que este não domine os meios de produção, que seja apenas para poder operar a produção:

A sociedade capitalista é baseada na propriedade privada dos meios de produção. Se os meios de produção são propriedade privada, isto significa que são exclusivos da classe dominante, da burguesia, dos capitalistas. Se o saber é força produtiva deve ser propriedade privada da burguesia. Na medida em que o saber se generaliza e é apropriado por todos, então os trabalhadores passam a ser proprietários de meios de produção. Mas é da essência da sociedade capitalista que o trabalhador só detenha a força de trabalho. Aí está a contradição que se insere na essência do capitalismo: o trabalhador não pode ter meio de produção, não pode deter o saber, mas, sem o saber, ele também não pode produzir, porque para transformar a matéria precisa dominar algum tipo de saber.

Assim, Bueno e Gomes (2012, p.8) afirmam que a classe burguesa, dona do meio de produção capitalista, é que determina a educação e observam que:

Se na sociedade escravista e na feudal as relações entre senhores e escravos, ou senhores e servos eram transparentes, porque havia não liberdade para os segundos, sob o signo do capitalismo, os trabalhadores aparentemente passaram a ter liberdade de escolher a forma de sobrevivência em uma sociedade onde não há emprego para todos. Com a crescente industrialização, a escolarização dos trabalhadores se tornou uma necessidade, inclusive para a manutenção dos interesses burgueses.

Assim, evidencia-se que a educação sempre se adaptou às demandas do meio de produção, pois a educação escolar é fruto das relações estabelecidas entre os meios de produção e as forças de trabalho que terminaram a instituição escolar, em cada contexto histórico.

Neste , atualmente, com as mudanças na estrutura da sociedade brasileira, decorrentes da influência das intervenções econômicas internacionais com preceitos capitalistas e liberais, a partir da adesão das prescrições do Consenso de Washington, pelo governo de Fernando Collor de Mello (1990 - 1992) e decorrentes continuidades pelo governo de Fernando Henrique Cardoso (1995 - 2002) e de Luis Inácio Lula da Silva (2003 - 2010) e sua sucessora, que interferem na crise da educação brasileira (AMARAL, 
2011), foram consolidados no Brasil os preceitos neoliberais de legalidade, burocracia, eficientismo, individualismo, competitividade, produtividade, liberação do mercado para controlar as ações privadas, diminuição e eliminação de barreiras tarifárias e fiscais, redução de gastos públicos, privatizações, aumento de impostos, etc. que repercutiram ou se reproduziram na educação superior brasileira.

Disso, Pachane (2004, p. 6), destacam como consequência que:

O Brasil tem vivenciado um período de diversas alterações no sistema de ensino superior, que englobam, além do crescimento destacado anteriormente, a expansão e flexibilização do sistema, mudanças na estrutura curricular (diretrizes curriculares), alterações nos critérios de ingresso nas IES, exigência de titulação do corpo docente, processos sistemáticos de avaliação, tanto em âmbito institucional como nacional, entre outros indicadores, muitos dos quais decorrentes da introdução de novas tecnologias na educação.

Podemos reconhecer que escola se constitui historicamente no local de produção do saber teórico, fragmentados da prática, seguindo as determinações do meio de produção. Esta fragmentação repercute no modo de aprender do aluno, nos currículos escolares e na organização escolar, que busca atender os interesses do capital, estabelecendo duas escolas, a dos ricos e a dos pobres, a dos que executam o trabalho manual e a dos que exercem o trabalho intelectual. Não diferente, as instituições de ensino superior também reproduzem esta fragmentação e distinção em suas matrizes curriculares.

A partir dessa contextualização, a seguir analisaremos o processo de formação do profissional da área de saúde no Ensino Superior e as consequências do modelo fragmentado e distinto de ensino.

\section{Os desafios para a formação do profissional da área de saúde}

Atualmente a formação do profissional da área da saúde passa pelo desafio de "romper paradigmas que a colocam na direção de uma formação com pertinência social e coerência com as Diretrizes Curriculares Nacionais (DCN)" (BRASIL, 2006b, p. 31).

A Constituição Federal de 1988 assegura ao Sistema Único de Saúde (SUS) a organização e integração do processo de ensino-aprendizagem dos graduados na área de saúde, porém Campos et al. (2001, p.54) analisam que isto não se aplica à prática institucional e que o fato de o mercado de trabalho do profissional da saúde, no SUS, ser amplo e rentável, em relação a outros, não parece gerar mudanças no ensino para os futuros profissionais de saúde. Neste contexto, afirmam que:

A desarticulação entre as definições políticas dos Ministérios da Saúde e da Educação têm contribuído para acentuar o distanciamento entre a formação dos profissionais e as necessidades do SUS (CAMPOS et al. 2001, p.54).

E a educação para os futuros profissionais da saúde deve contribuir para a melhoria da qualidade de vida da população e ser alicerçada pelos princípios e diretrizes do SUS, que preveem a universalidade, integralidade, descentralização, equidade e controle social.

Entre os profissionais de saúde, o modelo de formação neoliberalcapitalista encontrou sólido alicerce no já estruturado modelo 
flexneriano-biologicista-privatista, que privilegiou o tecnicismo em detrimento das preocupações sociais e se fundamentou nos princípios da fragmentação, da especialidade e da cura (PAIM, 2003 apud JUNIOR, 2007, p. 656).

Desta forma, o Ministério da Saúde e o da Educação afirmam que o modelo universitário, com autonomia nas decisões, fez que ocorresse um afastamento das reais necessidades do processo saúde-doença da população, de forma que:

Mesmo as transformações concretas da modelagem assistencial, que caminha em todo o mundo na direção de um modelo mais holístico e promotor da saúde encontra retardo para penetrar nas instituições de ensino. Ali, a reprodução de modelos de práticas pretéritas muitas vezes ainda prevalece. Superar um modelo biologicista, unicausal e centrado exclusivamente no biológico é um grande desafio hodierno (BRASIL, 2006b, p.7).

Por isso, o Ministério da Saúde e o da Educação buscam implementar estratégias de ensino que tragam integração da educação com a saúde, visando a melhoria do bem-estar do cidadão. As DCN, divulgadas no Parecer CNE/CES 1.133/2001, auxiliam na construção do projeto pedagógico dos cursos e na qualidade da formação oferecidas aos estudantes da área de saúde e buscam a integração do setor de saúde com a educação (BRASIL, 2006b).

A Política Nacional de Educação em Saúde, desenvolvida pelo Ministério da Saúde e da Educação, com estratégias e políticas voltadas para a formação do futuro profissional da saúde, parece evocar uma aproximação ideológica com o "comunismo primitivo", em que o trabalho e a educação eram desenvolvidos juntos, em que as pessoas aprendiam praticando, quando propõe para a formação profissional:

[...] o conceito ampliado de saúde; a utilização de metodologias ativas de ensino-aprendizagem, que considerem o trabalho como eixo estruturante das atividades; o trabalho em equipe multiprofissional e transdisciplinar; a integração entre o ensino e os serviços de saúde; o aperfeiçoamento da atenção integral à saúde e a qualificação da gestão (BRASIL, 2006b, p. 12).

No entanto, qualquer aproximação da concepção de trabalho e educação do "comunismo primitivo" sofre severas dificuldades para se efetivar no atual estágio da sociedade capitalista, já que a formação na área de saúde é institucionalizada e referencia atividades em outras instituições, inclusive internacionais, inviabilizando, muitas vezes, o atendimento às necessidades peculiares de cada país, região e comunidade, onde está inserida.

Mesmo assim, o "perfil ideológico" proposto pelas DCN concebe que seja formado nos cursos de graduação da área de saúde um currículo flexível, possibilitando ao graduando se adequar às mudanças que ocorrem no processo de aprendizagem e suas consequências para o trabalho, condição facilitada pelo uso dos recursos da EAD (BRASIL, 2006b - grifo nosso).

O perfil do profissional de saúde definido nas diretrizes é de um indivíduo com formação generalista, técnica, científica e humanista, com capacidade crítica e reflexiva, preparado para atuar, pautado por princípios éticos, no processo de saúde-doença em seus diferentes níveis de atenção. Enfatiza-se a perspectiva da integralidade da assistência, com 
senso de responsabilidade social e compromisso com a cidadania (BRASIL, 2006b, p.13).

Ainda segundo o Ministério da Saúde e da Educação:

As diretrizes orientam para currículos que contemplem elementos de fundamentação essencial no seu campo do saber ou profissão, numa concepção de que o indivíduo deve "aprender a aprender", engajado num processo de educação permanente. Propõe-se que os cursos de graduação sejam baseados em aprendizagem ativa, centrada no aluno, como sujeito da aprendizagem e no professor, como facilitador e mediador deste processo de ensino-aprendizagem. A diversificação de cenários e ambientes de aprendizagem centra-se na prática e na inserção do estudante no sistema público de saúde vigente, já no início da sua formação (BRASIL, 2006b, p.13).

É possível perceber o esforço retórico do Ministério da Saúde e do Ministério da Educação para superar as determinações do meio de produção, sobre a formação do profissional da área de saúde. O discurso manifestado nos documentos oficiais insiste e influencia os documentos institucionais e político-pedagógicos, mas dificilmente dão conta de alterar a realidade da formação ofertada. Este esforço registrado, a partir dos documentos oficiais, remete-se a intenção de dar "sentido para aqueles que acreditam que existe e existirá uma função pública reguladora que não deixe apenas à selva do mercado a regulação das práticas profissionais e assistenciais" (BRASIL, 2006a, p.7).

Mas, a vivência tem demonstrado que a política de formação concebida nas DCN influencia pouco a realidade desenhada pelo mercado, colocando os profissionais formadores e os profissionais em formação nos cursos presenciais em contextos desumanizados e fictícios da prática profissional, muito aquém da concepção almejada nas políticas públicas.

E esta situação é um fenômeno do próprio sistema econômico em que as instituições de ensino superior e de saúde estão inseridas, já que elas e seus sujeitos são afetados com as determinações da regulação do mercado.

Deste modo, a sociedade, as instituições formadoras, as instituições reguladoras e prestadoras de serviços públicos na área de saúde ficam diante da superação do desafio de alcançar cursos de graduação - a distância, mas principalmente os presenciais que registram toda a forma de precarização - na área de saúde para conseguirem, desenvolver e implementar currículos (i) que propiciem uma formação condizente com as frequentes mudanças do mercado de trabalho, que determinam mudanças para processo de ensinoaprendizagem; (ii) que propiciem a integração entre as instituições de ensino e saúde em prol do bem-estar da sociedade; (iii) que superem muitos dos falsos benefícios da autonomia universitária, como aquelas que facilitam o distanciamento da formação do profissional da área de saúde das reais situações da área; (iv) que redobre os esforços para que os futuros profissionais sejam formados para promover a melhoria dos cuidados e da qualidade de vida, conforme os princípios do SUS, em vez da comercialização da cura; e (v) principalmente, que supere a desarticulação entre as definições do SUS e do MEC e as determinações do mercado, na direção de uma formação para a oferta de um atendimento humanizado e engajado para superação das mazelas da sociedade. Desta forma, a seguir, analisaremos o discurso do FCFAS sobre a formação inicial do profissional da área de saúde pela modalidade EAD. 


\section{Análise e discussões sobre o discurso do FCFAS}

Compreendendo o processo da separação histórica da educação e trabalho e os desafios educacionais da formação do profissional de saúde discutidos anteriormente, analisaremos o discurso da área de saúde pelo "I Seminário sobre Ensino de Graduação a Distância na Área da Saúde", do Fórum dos Conselhos Federais da Área da Saúde que abordou temas como os aspectos políticos da EAD, as vantagens da graduação a distância, os elementos pedagógicos necessários para EAD, a visão dos Conselhos que já tinham experiência com EAD e as críticas sobre o assunto (FCFAS, 2011).

Os participantes do Seminário produziram um relatório, a fim de expor ao MEC o "posicionamento contrário à implementação de cursos de graduação a distância na área de saúde. Esse posicionamento (segundo eles - destaque nosso) foi formulado para assegurar uma educação de qualidade na área de saúde" (FCFAS, 2011, p. 14).

Ao tratar sobre a EAD podemos inferir que a modalidade ressurgiu no Brasil para democratizar o acesso ao ensino superior e para prioritariamente suprir a necessidade de formação inicial e continuada de professores da área de educação (ALONSO, 2010).

Assim, Bueno e Gomes (2012, p. 2) evidenciam que sempre houve mudanças na estrutura escolar do Brasil, para historicamente suprir as necessidades das transformações e determinações dos meios de produção, frente à sociedade, quando afirmam que:

Temos que aqui reforçar a ideia que a estrutura escolar é fruto de uma construção histórica, produto social e produtora das relações materiais existentes entre os homens. Como é social, é mutável, pois foi constituída pelos homens, em suas interações e intervenções no meio em cada momento histórico. Em suma, negamos com todas as letras uma visão ahistórica que trata a educação escolar como um tipo de organização que sempre existiu, como se não houvesse um passado diferente e a possibilidade de alternativas substancialmente superiores a que presenciamos.

Com a globalização da economia, as imposições do modelo capitalista-neoliberal e o surgimento das novas tecnologias, também determinaram um modelo de escola flexibilizada, para dar conta de suprir a demanda pedagógica e social da classe trabalhadora (PRETI, 1998, p.19).

Discutir a expansão da EAD para o ensino superior, algumas questões frequentemente são elencadas, como a qualidade do ensino oferecido na $E A D$, o que é possível realizar no processo de ensino aprendizagem e as restrições legais do uso da EAD para a formação superior profissional. Como referencial norteador que qualifica, credencia, regula, supervisiona e avalia cursos na modalidade de EAD, no Brasil existem as bases legais que fornecem suporte para esta modalidade.

Devemos destacar que a EAD é considerada legal, como modalidade de ensino e não uma "ferramenta", como está exposto no relatório do FCFAS, por isto, o ensino, na modalidade de educação a distância tem possibilitado, nas últimas décadas, o acesso à formação e à possibilidade de especializações para o trabalhador ocupar novas posições de trabalho no meio de produção, provocando fortes mudanças no perfil do aluno e no processo de ensino aprendizagem.

Podemos apontar algumas críticas do FCFAS ao EAD para as graduações da área de saúde. Uma delas é que não haverá garantia de bons laboratórios, profissionais do setor administrativo e docentes qualificados, com polos semelhantes aos da IES e que sejam 
compatíveis com o número de alunos pela modalidade EAD. O FCFAS também pontua que é difícil viabilizar supervisão de estágio pelo EAD (FCFAS, 2011). Estas questões poderiam ser respondidas pela legislação que segundo Ministério de Educação e Secretaria de Educação a Distância, com o Decreto 5.622 foi estabelecido que:

A política de garantia de qualidade no tocante aos variados aspectos ligados à modalidade de educação a distância, notadamente ao credenciamento institucional, supervisão, acompanhamento e avaliação, harmonizados com padrões de qualidade enunciados pelo Ministério da Educação (BRASIL 2007b, p. 5).

A Portaria Normativa 2, de 10 de janeiro de 2007, que "dispõe sobre os procedimentos de regulação e avaliação da educação superior na modalidade a distância", reforça o que determina o decreto 5.622, ao prescrever no $\S 2^{\circ}$ do Artigo $1^{\circ}$ que:

O pedido de credenciamento para EAD será instruído com os documentos necessários à comprovação da existência de estrutura física e tecnológica e recursos humanos adequados e suficientes à oferta da educação superior a distância, conforme os requisitos fixados pelo Decreto $\mathrm{n}^{\circ} 5.622$, de 2005 e os referenciais de qualidade próprios.

Assim, o MEC intensificou a avaliação dos cursos aplicando diligências àqueles que não atendiam a legislação vigente, iniciando um processo de reformulação das metodologias de ensino a distância e da oferta das condições de estrutura e infraestrutura condizentes com os pressupostos de qualidade descritos nos quesitos dos Referenciais de qualidade de Ensino Superior a Distância.

O FCFAS também aponta questionamentos quanto à formação prática do aluno da área de saúde pela modalidade de ensino a distância e diz que:

As Diretrizes Curriculares Nacionais para os cursos da área da Saúde estabelecem atividades práticas desde o início da formação, visando a construção de aproximações e aprofundamento diante dos problemas concretos da realidade. Enfatizou-se que a formação em saúde está centrada no cuidado com o ser humano. Logo, questionou-se como desenvolver este lado humanístico e profissional à distância? Na EAD os conteúdos práticos profissionais sem relação com o paciente e distante das necessidades de saúde perdem o sentido (FCFAS, 2011, p. 11).

Tal questionamento nos remete à dicotomia teórico-prático que também ocorrem nos cursos presenciais superiores na área de saúde. A exemplo dessa nossa assertiva, temos o documento produzido pelo MEC em 2006, denominado "Aderência dos cursos de graduação em Enfermagem, Medicina e Odontologia às diretrizes curriculares nacionais", que apresenta uma das análises realizadas no curso de Medicina com baixa aderência às DCN, onde se observou:

[...] que os cursos avaliados preconizam a formação de um profissional com atitudes éticas, responsável, humanista, crítico e com uma postura profissional reflexiva. Todavia, a lógica estruturante dos currículos das escolas do primeiro intervalo inter-quartil é a da organização por disciplinas, centrada no professor, baseada no conhecimento e com avaliação do estudante predominantemente cognitiva. Os laboratórios de ensino estão restritos às ciências básicas. A integração de conteúdos 
curriculares, quando presente, é pontual e concentrada nas ciências básicas. Percebe-se uma falta de clareza na forma de inserção dos conteúdos da saúde coletiva ao longo do processo de formação (BRASIL, 2006b, p. 109).

Ainda nos cursos de Enfermagem que possuem baixa aderência à DCN pode se observar a partir de relatos colhidos que as:

Aulas práticas se limitam ao laboratório e só há esporadicamente visitas técnicas aos outros cenários de prática que só se realizam no $7^{\circ}$ e $8^{\circ}$ período quando se efetivam os momentos de desenvolvimento das habilidades (BRASIL, 2006b, p. 78).

Esses são alguns exemplos que contrariam o discurso do FCFAS, que se posiciona com um discurso contrário à qualidade de ensino oferecido pela modalidade EAD, destacando os mesmos problemas persistentes da modalidade presencial, como se fossem exclusivos da EAD, em vez de estabelecer um discurso crítico às mudanças ocorridas no trabalho e nas relações sociais, visto que ainda sofremos influências da educação tradicional, fragmentada, hierarquizada dos tempos hegemônicos do toyotismo, mesmo que as políticas educacionais deixem a impressão que estão servindo às demandas do trabalhador, no sentido de democratizar o ensino.

\section{Palavras finais}

Relatamos que a separação da educação e trabalho surgiu com a propriedade privada e a divisão da sociedade em classes, proporcionando distintos tipos de educação, sendo uma para a classe trabalhadora e outra para os filhos dos proprietários e que a primeira pautava-se pela prática e a segunda pela teoria e que foi sob a égide da educação pública institucionalizada que, desde então, a questão da dissociação teoria e prática se confirmou inerente à educação, não havendo relação da origem dessa dicotomia com a EAD.

Com a institucionalização da educação podemos observar as consequências do modo de educação tradicional favorecendo a manutenção da sociedade burguesa e servindo de parâmetros para avaliação de outros modos de educação, ignorando as possibilidades de interação, comunicação, ensino e aprendizagem para além da educação tradicional, que por si só, já não atende as necessidades dos sujeitos, da sociedade e do meio de produção. As mudanças nos e dos meios de produção, que determinaram os caminhos da escola e das IES, também sofreram modificações que redefiniram a organização e as funções na sociedade, pois passaram a demandar imperativamente a formação escolar dos profissionais para ocuparem os postos de trabalho do meio de produção, ampliando a demanda pela formação escolar e profissionalização do trabalhador pela educação. A EAD vai emergir neste contexto como uma possibilidade de acesso à formação para os trabalhadores.

Reconhecemos que escola se constitui na história como o local de produção do saber teórico, fragmentados da prática, seguindo as determinações do meio de produção. Não diferente da escola, as instituições de ensino superior reproduzem esta fragmentação em suas matrizes curriculares, seja no ensino presencial ou no a distância, repercutindo no modo de aprender do aluno, na organização da instituição que busca atender os interesses do capital. 
A formação do profissional da área de saúde passa por desafios e deve contribuir para a melhoria da qualidade de vida da população e ser alicerçada pelos princípios e diretrizes SUS. Porém, o modelo universitário atual, com práticas de ensino tradicionais e presencias, distancia o conhecimento do aluno das reais necessidades do processo saúdedoença da população, não sendo isso um condicionante exclusivo da EAD.

As Políticas de Educação em Saúde têm como proposta a formação do aluno com um perfil generalista, com trabalho em equipe multiprofissional e transdisciplinar, com currículos flexíveis, parecendo evocar o "comunismo primitivo", porém a formação na área de saúde é institucionalizada, inviabilizando, muitas vezes, o atendimento às necessidades peculiares de cada comunidade, momento histórico e região, onde está inserida.

Os contextos desumanizados e fíctícios desenhados pela realidade e pelas determinações do mercado assentam os profissionais formadores da área de saúde e aqueles que estão em formação tangencialmente às concepções almejadas pelas políticas públicas e pelo modelo de formação concebida nas DCN.

Por isto, acreditamos que cursos de formação da área de saúde têm o desafio de desenvolver currículos mais flexíveis atentos ao processo de ensino-aprendizagem, formando futuros profissionais atentos às reais situações da área de saúde, na direção de uma formação para a oferta de um atendimento humanizado e engajado para superação das enfermidades da sociedade, seja pela educação presencial ou pela educação a distância, mas principalmente por aquela que lhe for acessível, resguardando as diretrizes curriculares nacionais, as do SUS e a legislação educacional vigente.

$\mathrm{Na}$ análise do debate ocorrido no "I Seminário sobre Ensino de Graduação a Distância na Área da Saúde", do Fórum dos Conselhos Federais da Área da Saúde levantamos que foram abordados temas como os aspectos políticos da EAD e que o posicionamento contrário dos Conselhos da área de saúde à EAD nos cursos de graduação é devido à suposta falta de qualidade do ensino desta modalidade, implicado ao grande número de alunos por estágio e agravado pela falta de formação técnica administrativa e docente dos profissionais que atuam na educação a distância.

Entretanto, é exposto na literatura que a modalidade de educação a distância tem possibilitado, nas últimas décadas, o acesso à formação e à possibilidade de especializações para o trabalhador ocupar novas posições de trabalho no meio de produção. Este contexto causou uma expansão da oferta de cursos a distância e o MEC intensificou as avaliações e diligências àqueles cursos e instituições que não atendem a legislação vigente.

As experiências de avaliação do MEC em 2006, quando à aderência de alguns cursos da área de saúde às DCN, deixaram explicito que a problemática de ensino de qualidade na área de saúde, não está centrada na modalidade de ensino e sim nas mudanças ocorridas no trabalho, nas relações sociais e nas influências que ainda sofremos da educação tradicional, que é fragmentada, hierarquizada.

Por fim, temos a contribuir com o entendimento de que é preciso ampliar o debate sobre a formação de profissionais da área de saúde pela modalidade a distância e não o reduzir a argumentos preconceituosos, que reproduzem artificialmente os preceitos tradicionais e conservacionistas do modelo de escola burguesa, como se esta fosse, ainda, uma reserva da área de saúde.

\section{Referências}

AMARAL, N.C. O vínculo avaliação-regulação-financiamento nas IES brasileiras: desafio para a gestão institucional. PBPAE, Porto Alegre, v.27, n.1, p. 95-108, jan./abr. 2013. 
ALONSO, K. M. A expansão do ensino superior no Brasil e a EAD: dinâmicas e lugares. Rev. Educ. Soc., Campinas, v. 31, n. 113, p. 1319-1335, out./dez. 2010.

BRASIL. Decreto ${ }^{\circ} 5.773$, de 09 de maio de 2006. Diário Oficial [da] República Federativa do Brasil. Brasília, DF, 9 mai. 2006a.

BRASIL. Ministério da Educação, Ministério da Saúde. Aderência dos cursos de graduação em Enfermagem, Medicina e odontologia às diretrizes curriculares nacionais. Brasília, 162 p 2006b. Disponível em < http://abeno.org.br/arquivos/downloads/download_20111215103241.pdf > Acesso em: 18 fev. 2015.

BRASIL. Decreto ${ }^{\circ} 6.303$, de 12 de dezembro de 2007. Diário Oficial [da] República Federativa do Brasil. Brasília, DF, 12 dez. 2007a.

BRASIL. Referenciais de qualidade para Educação Superior a Distância. Diário Oficial [da] República Federativa do Brasil. Brasília, DF, ago. 2007 b.

BRASIL. Portaria Normativa $\mathrm{n}^{\circ}$ 02, de 10 de janeiro de 2007, Diário Oficial [da] República Federativa do Brasil. Brasília. DF, 10 jan. 2007c.

BUENO, J.L.P; GOMES, M.A.O. Uma análise histórico-crítica da formação de professores com tecnologias de informação e comunicação, Rev. Cocar, v. 6, n. 10, p. 119, Jun. 2012.

CAMPOS, F.E. et al. Caminhos para Aproximar a Formação de Profissionais de Saúde das Necessidades da Atenção Básica, Rev. Brasileira de Educação Médica, v. 25, n. 2, maio/ago. 2001.

FÓRUM dos Conselhos Federais da Área de Saúde. Relatório do I Seminário sobre Ensino de Graduação à Distância na Área da Saúde do Fórum dos Conselhos Federais da Área da Saúde - FCFAS. Brasília: 2011, 15 p. Disponível em< http://www.cfess.org.br/arquivos/Documento_Final_EaD_03.2011.pdf > Acesso em: 18 fev. 2015.

JUNIOR, J. P. B. Formação em fisioterapia no Brasil: reflexões sobre a expansão do ensino e os modelos de formação, Rev. História, Ciências, Saúde, Rio de Janeiro, v.16, n.3, p.655-668, jul./set. 2009.

PACHANE, Graziela Giusti, Políticas de formação pedagógica do professor universitário: Reflexões a partir de uma experiência. Disponível em: < http://www.anped.org.br/reunioes/27/gt11/t116.pdf > Acesso em: 20 abr. 2015.

PRETI, O. Educação a Distância e globalização: desafios e tendências, R. Bras. Est. pedag., Brasília, v.79, n.191, p.19-30, jan./abr. 1998.

SAVIANI, D. O trabalho como princípio educativo frente às novas tecnologias. In: FERRETTI, Celso J. et al. (orgs.) Novas tecnologias, trabalho e educação: um debate multidisciplinar. Petrópolis: Vozes, 1994. 
SAVIANI, D. Trabalho e educação: fundamentos ontológicos e históricos, Rev. Bras. Educ., ISSN 1413-2478, v.12, n.34, Rio de Janeiro, Jan./Abr. 2007.

\section{Notas}

${ }^{1}$ Docente de Instituição de Ensino Superior privada - Faculdade São Lucas - RO. Mestre em Educação da Universidade Federal de Rondônia - Unir. Membro do grupo de pesquisa "Praxis" - UNIR. E-mail: 7dalianne@gmail.com

${ }^{2}$ Graduado em letras. Professor-pesquisador da área de Formação de professores; Tecnologia educacional; Tecnologias aplicadas à educação; Educação a distância; Letramento e inclusão digital e Cultura, mídia e educação. Mestre e Doutor em Engenharia de Produção. Atua como professor do Departamento de Ciências da Educação da UNIR. Coordenador mestrado profissional em educação. Atua como consultor do MEC. Membro do grupo de pesquisa "Educa". E-mail: 7lucas@ gmail.com

${ }^{3}$ Doutorado (2008) em História e Filosofia da Educação pela Universidade Estadual de Campinas. Professor da UNIR no Departamento de Ciências da Educação, nos temas: Fundamentos e práticas do ensino de História, Estado e Políticas Públicas em Educação, Estrutura e funcionamento de Ensino, História da Educação e Trabalho e Educação. É professor permanente do Programa de Mestrado Acadêmico em Educação e do Mestrado Acadêmico em História e Estudos Culturais. E-mail: marcooliveiragomes@yahoo.com.br

Recebido: junho-15 Aprovado: dezembro-15 